\title{
Is magnetic resonance elastography superior to transient elastography for the diagnosis of liver fibrosis?
}

\author{
Jiangfeng Wu, Yun Jin, Xingbo Sun \\ Department of Ultrasound, The Affiliated Dongyang Hospital of Wenzhou Medical University, Dongyang, China \\ Correspondence to: Jiangfeng Wu. Department of Ultrasound, The Affiliated Dongyang Hospital of Wenzhou Medical University, No. 60 Wuning \\ West Road, Dongyang 322100, Zhejiang, China. Email: wjfhospital@163.com. \\ Comment on: Bi J, Liu L, Qin T. Comparison of magnetic resonance elastography and transient elastography in the diagnosis of hepatic fibrosis: a \\ systematic review and meta-analysis. Ann Palliat Med 2021;10:8692-700.
}

Submitted Oct 13, 2021. Accepted for publication Nov 16, 2021.

doi: 10.21037/apm-21-2964

View this article at: https://dx.doi.org/10.21037/apm-21-2964

We read with great interest the recent meta-analysis written by Bi and colleagues entitled "comparison of magnetic resonance elastography (MRE) and transient elastography (TE) in the diagnosis of hepatic fibrosis: a systematic review and metaanalysis" (1). The authors highlight MRE may be a useful, noninvasive method for the assessment of liver fibrosis in patients with chronic liver disease. We strongly agree with the views expressed by the authors, but we have several comments on this study.

First, in the methods section of the abstract, Bi et al. depicted that pooled sensitivity (SEN), specificity (SPE), positive and negative likelihood ratios (PLR and NLR), and diagnostic odds ratio (DOR) were calculated. But, in this meta-analysis, the pooled outcome variable was odds ratios (ORs) that were referred in the statistical analysis section and the combined SEN, SPE, PLR, and NLR were not referred in this study. So, we think that the unnecessary indicators depicted in the abstract would undoubtedly result in misunderstanding.

Second, according to the results, MRE showed higher sensitivity than $\mathrm{TE}(\mathrm{P}=0.03)$ in the diagnosis of stage $\mathrm{F} 0-\mathrm{F} 1$ liver fibrosis and showed higher specificity for diagnosing stage $\mathrm{F} 2-\mathrm{F} 4$ liver fibrosis $(\mathrm{P}<0.0001)$, while there was no difference regarding SEN of MRE and TE to F2-F4 liver fibrosis $(\mathrm{P}=0.19)$ and the SPE of MRE and TE to F0-F1 liver fibrosis $(\mathrm{P}=0.70)$. Furthermore, in the conclusions section, the authors revealed that MRE is superior to TE in diagnosing hepatic fibrosis of different stages in the field of SEN and SPE. We believe that the interpretation of the results is not appropriate. The rational interpretation of the results is that MRE is superior to TE in diagnosing stage F0-F1 hepatic fibrosis in the field of sensitivity and stage F2-F4 hepatic fibrosis in the field of specificity.

Finally, sensitivity analysis is carried out by excluding one study at a time to evaluate the effect on the pooled results (2). In the results of sensitivity and publication bias analyses section, the authors performed the sensitivity analysis by omitting Tafur's 2020 study (3) and did not further exclude the other included studies. Then, we consider that the sensitivity analysis was incomplete.

We highlight these issues merely to promote the clinical utility and relevance of Bi et al.'s study and recommend that the authors of similar such studies may consider replicating these additional points.

\section{Acknowledgments}

Funding: None.

\section{Footnote}

Provenance and Peer Review: This article was a standard submission to the journal. The article did not undergo external peer review.

Conflicts of Interest: All authors have completed the ICMJE uniform disclosure form (available at https://dx.doi. org/10.21037/apm-21-2964). The authors have no conflicts 
of interest to declare.

Ethical Statement: The authors are accountable for all aspects of the work in ensuring that questions related to the accuracy or integrity of any part of the work are appropriately investigated and resolved.

Open Access Statement: This is an Open Access article distributed in accordance with the Creative Commons Attribution-NonCommercial-NoDerivs 4.0 International License (CC BY-NC-ND 4.0), which permits the noncommercial replication and distribution of the article with the strict proviso that no changes or edits are made and the original work is properly cited (including links to both the formal publication through the relevant DOI and the license).
See: https://creativecommons.org/licenses/by-nc-nd/4.0/.

\section{References}

1. Bi J, Liu L, Qin T. Comparison of magnetic resonance elastography and transient elastography in the diagnosis of hepatic fibrosis: a systematic review and meta-analysis. Ann Palliat Med 2021;10:8692-700.

2. Lin $Z$, Lin $\mathrm{R}, \mathrm{Wu} \mathrm{H}$, et al. Elastography for the differential diagnosis of malignant versus benign testicular lesions: a meta-analysis. Ultrasonography 2021;40:465-73.

3. Tafur M, Cheung A, Menezes RJ, et al. Risk stratification in primary sclerosing cholangitis: comparison of biliary stricture severity on MRCP versus liver stiffness by MR elastography and vibration-controlled transient elastography. Eur Radiol 2020;30:3735-47.
Cite this article as: $\mathrm{Wu} J$, Jin $\mathrm{Y}$, Sun $\mathrm{X}$. Is magnetic resonance elastography superior to transient elastography for the diagnosis of liver fibrosis? Ann Palliat Med 2021;10(12):12917-12918. doi: 10.21037/apm-21-2964 